\title{
Plasmid Curing and Generation of Mutations Induced with Ethidium Bromide in Streptomycetes
}

\author{
By RETO CRAMERI, ${ }^{1}$ JULIAN E. DAVIES ${ }^{*} \dagger$ AND RALF HÜTTER ${ }^{2}$ \\ ${ }^{1}$ Biogen SA, PO Box 1211, Geneva 24, Switzerland \\ ${ }^{2}$ Mikrobiologisches Institut, Eidgenossische Technische Hochschule, ETH Zürich, \\ CH-8093 Zürich, Switzerland
}

(Received 30 July 1985; revised 17 October 1985)

The DNA-intercalating agent ethidium bromide was used to eliminate plasmid DNA from streptomycetes. Other mutational events associated with chromosome changes occurred at high frequency; they resulted in phenotypic changes such as loss of enzyme activity, antibiotic resistance or ability to sporulate.

\section{INTRODUCTION}

Following reports of plasmid 'curing agents' which implied the possible involvement of extrachromosomal elements in the biosynthesis of secondary metabolites (Gregory \& Shyu, 1961), many studies of unstable genetic elements have been published. Plasmid involvement in the genus Streptomyces has been postulated for numerous characteristics such as fertility (Vivian, 1971; Friend et al., 1978), melanin formation (Gregory \& Huang, 1964a, $b$; Shaw \& Piwowarski, 1977), differentiation (Okanishi et al., 1970; Pogell, 1979), antibiotic sensitivity (Shaw \& Piwowarski, 1977) and antibiotic production (Hopwood, 1978; Hopwood \& Merrick, 1977; Schrempf, 1981). It has been argued that a plasmid has been involved in the expression of a given phenotype when that phenotype has shown spontaneous instability and/or curing, infectious transfer during crosses, non-linkage to chromosomal markers, and correlation with presence or loss of plasmid DNA. The pros and cons of these arguments have been discussed extensively (Hopwood, 1978), and with a few notable exceptions it has been difficult to provide a conclusive demonstration of the role of plasmids in the expression of a given phenotype.

One of the best illustrations is the case of chloramphenicol production in Streptomyces venezuelae. The ability to produce chloramphenicol in this strain is sensitive to curing agents (Okanishi \& Umezawa, 1978; Michelson \& Vining, 1978) and the first genetic analysis of crosses showed no linkage of production genes with chromosomal markers (Akagawa et al., 1975). $S$. venezuelae contains plasmid DNA (Malik, 1977), and a correlation between plasmid presence and production of chloramphenicol has been found (Okanishi \& Umezawa, 1978). A more accurate analysis of crosses involving chloramphenicol-producing and non-producing strains showed that the genes responsible for chloramphenicol production were, in fact, localized chromosomally (Akagawa et al., 1979), a result that was confirmed by DNA analysis of producing and non-producing strains (Ahmed \& Vining, 1983). Moreover, Malik (1980) demonstrated that plasmid-less, chloramphenicol non-producing $S$. venezuelae strains acquired the ability to produce chloramphenicol after mutagenic treatment. This excluded the possibility that the biosynthetic genes for chloramphenicol were plasmid coded.

A contrary example is the case of $S$. glaucescens. This strain shows a high spontaneous instability, especially of the genes required for streptomycin resistance and melanin formation (Freeman \& Hopwood, 1978; Hütter et al., 1981). It was demonstrated that the genes controlling

† Present address: Institut Pasteur, 28 rue du Dr Roux, 75724 Paris, France. 
both of these functions were linked to chromosomal genes (Crameri et al., 1983, 1984) and that the instability was due to independent, large deletions of chromosomal DNA (Hintermann et al., 1984; Hintermann \& Hütter, 1984)

These studies left open the question of whether ethidium bromide was a useful agent for plasmid-curing of streptomycetes and in this paper we have examined this point.

\section{METHODS}

Bacterial strains and plasmids. The Streptomyces strains used were S. lividans 1326 (Lomovskaya et al., 1972) and S. glaucescens GLAO (Hütter et al., 1981). The multicopy plasmids pIJ303 (thiostrepton resistance), pIJ211 (neomycin resistance) (Kieser et al., 1982), pIJ702 (Katz et al., 1983) and the low copy number plasmid pIJ61 (Thompson et al., 1982b) were used. pIJ702 contains the thiostrepton-resistance gene and a tyrosinase gene from S. antibioticus which confers the ability to form black melanin haloes on indicator plates (Katz et al., 1983). pIJ61 confers resistance towards thiostrepton and neomycin (Thompson et al., 1982b).

Media and culture conditions. Strains were grown on yeast extract/malt extract agar (Pridham et al., 1956/7) at $30{ }^{\circ} \mathrm{C}$ until sporulation. Spore suspensions were prepared either from agar slants or plates using $50 \%(\mathrm{v} / \mathrm{v})$ glycerol and stored at $-20^{\circ} \mathrm{C}$. Yeast extract/malt extract medium was used as complete medium for all experiments described. Minimal medium was the standard medium used for segregational analysis in S. glaucescens (Crameri et al., 1983). Liquid cultures for plasmid isolations were in tryptic soya broth CM-129 (Oxoid) according to Kieser (1984)

Transformation procedure and selection of transformants. Plasmid DNA was introduced into $S$. lividans or $S$. glaucescens protoplasts (Thompson et al., 1982a) and transformants detected by overlaying plates with $2.5 \mathrm{ml}$ soft agar (Kieser et al., 1982) containing thiostrepton $\left(200 \mu \mathrm{g} \mathrm{ml}^{-1}\right)$ or neomycin $\left(100 \mu \mathrm{g} \mathrm{ml}^{-1}\right)$.

Plasmid stability. This was determined by measuring the stable inheritance of antibiotic resistance. The percentage of thiostrepton- or neomycin-resistant colonies per sporulation round on antibiotic-free complete medium plates was determined (Kieser et al., 1982).

Curing experiments. These were done using ethidium bromide (Sigma) at various concentrations in complete medium plates inoculated with serial dilutions of filtered stock spore suspensions.

Detection of plasmid loss. This was done by replica-plating sporulated colonies on to complete medium agar containing thiostrepton $\left(20 \mu \mathrm{g} \mathrm{ml}^{-1}\right)$ or neomycin $\left(10 \mu \mathrm{g} \mathrm{ml}^{-1}\right)$. Physical absence of plasmid DNA was demonstrated by agarose gel electrophoresis after alkaline lysis and phenol/chloroform extraction (Kieser, 1984).

Detection of other mutational events. Streptomycin sensitivity in S. glaucescens was determined according to Crameri et al. (1983); the inability to produce melanin was detected as described by Crameri et al. (1984). Chloramphenicol sensitivity in $S$. lividans was detected after replica-plating on media containing chloramphenicol $\left(10 \mu \mathrm{g} \mathrm{m}^{-1}\right)$, and arginine auxotrophy after replica-plating on minimal medium containing arginine (1 mM) (Altenbuchner \& Cullum, 1984).

\section{RESULTS \\ Plasmid stability}

In the absence of ethidium bromide, the test plasmids pIJ61 and pIJ702 in S. lividans as well as pIJ303 in S. glaucescens were completely stable after several rounds of growth and sporulation (Table 1). Plasmid stability was determined by comparing the number of c.f.u. on complete media with and without antibiotic. Between 2500 and 5000 colonies per sporulation cycle on antibiotic-free solid medium were tested. Since pIJ 211 is highly unstable in S. glaucescens (Table 1), curing experiments with this strain were done using the stably inherited plasmid pIJ 303.

\section{Table 1. Plasmid stability}

\begin{tabular}{|c|c|c|c|c|c|c|c|c|}
\hline \multirow[b]{2}{*}{ Strain } & \multirow{2}{*}{$\begin{array}{c}\text { Transformation } \\
\text { by plasmid* }\end{array}$} & \multicolumn{7}{|c|}{$\begin{array}{l}\text { Percentage antibiotic-resistant colonies } \\
\text { after round(s) of growth without antibiotic }\end{array}$} \\
\hline & & 0 & 1 & 2 & 3 & 4 & 5 & 6 \\
\hline $\begin{array}{l}\text { S. glaucescens } \\
\text { S. glaucescens }\end{array}$ & $\begin{array}{l}\text { pIJ211 }\left(\mathrm{Neo}^{\mathrm{R}}\right) \\
\text { pIJ303 }\left(\mathrm{Thio}^{\mathrm{R}}\right)\end{array}$ & 100 & 67 & 44 & 33 & 22 & 15 & 12 \\
\hline $\begin{array}{l}\text { S. lividans } \\
\text { S. lividans }\end{array}$ & $\begin{array}{l}\left.\text { pIJ702 (Thio }{ }^{R}\right) \\
\text { pIJ61 }\left(\mathrm{Neo}^{R} \text { Thio }^{R}\right)\end{array}$ & 100 & 100 & 100 & 100 & 100 & 100 & 100 \\
\hline
\end{tabular}

\footnotetext{
* Neo, neomycin; Thio, thiostrepton.
} 


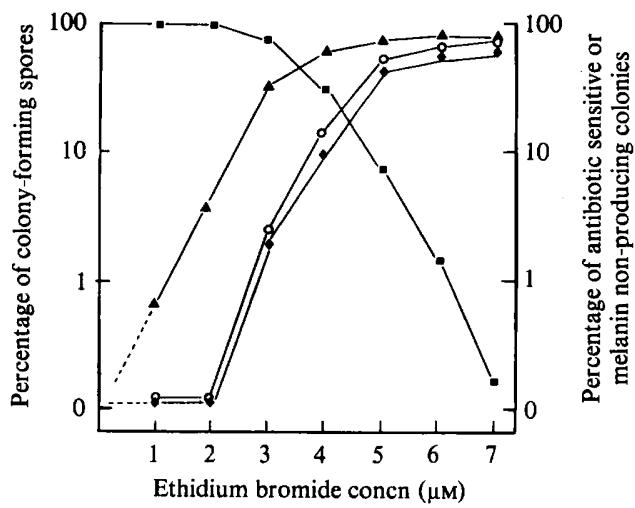

Fig. 1. Curing of pIJ303 from S. glaucescens and generation of melanin-negative and streptomycinsensitive colonies. The surviving colonies $(\square)$ are given as a percentage of the original number of colonies; thiostrepton-sensitive $(\Delta)$, melanin-negative $(O)$ and streptomycin-sensitive $(\diamond)$ colonies are given as a percentage of the surviving colonies.

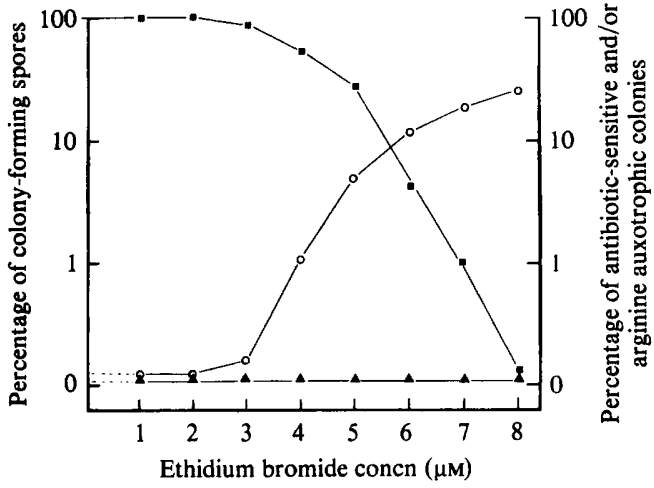

Fig. 2

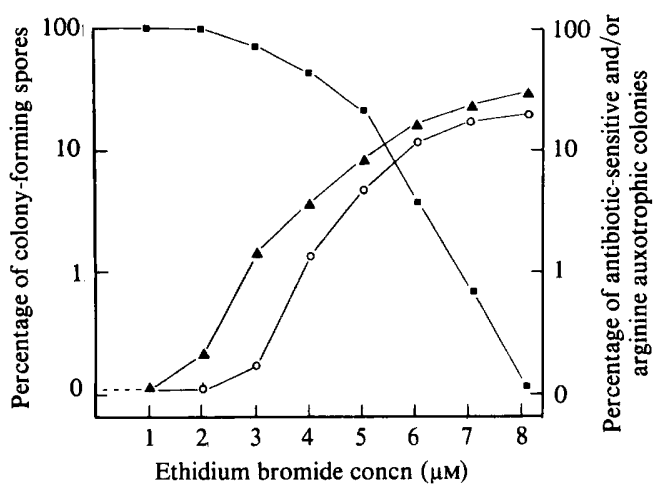

Fig. 3

Fig. 2. Effects of ethidium bromide in S. lividans carrying pIJ702. The surviving colonies ( $\square$ ) are given as a percentage of the original number of colonies; thiostrepton-sensitive $(\boldsymbol{\Lambda})$ and chloramphenicolsensitive arginine-negative $(O)$ colonies are given as a percentage of the surviving colonies.

Fig. 3. Effects of ethidium bromide in $S$. lividans carrying pIJ61. For explanation of the symbols see Fig. 2.

\section{Killing effect of ethidium bromide, plasmid-curing and generation of other mutations}

S. glaucescens. Fig. 1 summarizes the results of a typical curing experiment using pIJ303containing $S$. glaucescens spores. This strain can be almost $100 \%$ cured of the plasmid by ethidium bromide concentrations that result in more than $90 \%$ of either killed spores or colony inhibition. Under these conditions ethidium bromide generated melanin-negative and streptomycin-sensitive colonies at high frequencies. Twenty thiostrepton-resistant and twenty thiostrepton-sensitive colonies from plates containing $4 \mu \mathrm{M}$-ethidium bromide were analysed for the presence of plasmid DNA on agarose gels after mini preparations by alkaline lysis. A strict correlation between plasmid presence and thiostrepton resistance was found (data not shown).

$S$. lividans. The results obtained routinely with this strain are summarized in Figs 2 and 3. Plasmid pIJ702 is completely refractory to curing. In addition, among 85637 surviving colonies grown in the presence of $7 \mu \mathrm{M}$-ethidium bromide, no thiostrepton-sensitive or melanin-negative colonies could be detected. On the other hand, plasmid pIJ61, a low copy number plasmid, could be cured efficiently at high ethidium bromide concentrations (Fig. 3), but less efficiently than 
pIJ303 in $S$. glaucescens. When plasmid mini preparations of thiostrepton- and neomycinresistant colonies were analysed by agarose gel electrophoresis, plasmids of different sizes were observed, suggesting that plasmid deletions (between $1-10 \%$ ) occurred in the presence of ethidium bromide (see Discussion). A restriction nuclease digestion analysis of purified plasmids confirmed this hypothesis (data not shown).

During this experiment it was noticed that a substantial number of the survivors were unable to sporulate (Figs 2 and 3); 25 such sporulation-negative colonies were studied. All were highly sensitive to chloramphenicol $\left(8 \mu \mathrm{g} \mathrm{ml}^{-1}\right)$ and were able to grow on minimal medium supplemented with arginine $(1 \mathrm{mM})$ or argininosuccinate $(2 \mathrm{mM})$ but not on media supplemented with ornithine $(2 \mathrm{mM})$ or citrulline $(2 \mathrm{mM})$. This suggests the loss of argininosuccinate synthetase, an event that occurs spontaneously in this strain at low frequencies (Altenbuchner \& Cullum, 1984).

\section{DISCUSSION}

We have demonstrated that the DNA-intercalating agent ethidium bromide can be used to eliminate certain plasmids at high efficiency from Streptomyces strains. The availability of selectable plasmid vectors (Kieser et al., 1982; Thompson et al., 1982b) has facilitated this work substantially, because putative 'cured' colonies can be screened as antibiotic-sensitive clones. However, ethidium bromide does not only eliminate plasmids and S. glaucescens shows multiple effects of treatment. This strain has a high genetic instability with respect to several phenotypes (Hütter et al., 1981), including streptomycin resistance. This resistance marker is lost spontaneously (Freeman \& Hopwood, 1978; Crameri et al., 1983); biochemically, streptomycinsensitive mutants lack a streptomycin-6-phosphotransferase (Ono et al., 1983; Hintermann et al., 1984). Treatment of spores with ethidium bromide can increase the number of sensitive mutants to a level of $90 \%$ of surviving colonies (Suter, 1978; this work). The mutant strains are genetically homogeneous, and the $s t r S$ mutation maps chromosomally (Crameri et al., 1983). Moreover, strS mutants show large deletion(s), including deletion of the structural gene coding for a streptomycin-6-phosphotransferase as demonstrated by DNA hybridization experiments using the cloned gene (Hintermann et al., 1984). Analogous behaviour is seen for the ability to produce melanin, a black pigment produced by tyrosinase-catalysed oxidation of tyrosine. In this case, also, the mutants appear to be genetically homogeneous and can be mapped chromosomally (Crameri et al., 1984). Phenotypic instability of this trait occurs spontaneously (Hütter et al., 1981) and can be increased significantly by ethidium bromide treatment (Suter, 1978; this work). In the case of tyrosinase-negative variants, analysis of DNA using a cloned gene as probe showed that ethidium bromide generated mutants which lacked the structural gene coding for tyrosinase and its flanking regions (Hintermann \& Hütter, 1984). Similar mutations in another melanin-producing streptomycete, $S$. reticuli, are also due to deletion of the structural gene coding for tyrosinase (Schrempf, 1983). No physical evidence exists for a plasmid-like molecule present in the wild-type strain of S.glaucescens (Hintermann et al., 1984).

The best-investigated strain for in vitro genetic manipulations of streptomycetes, $S$. lividans (Hopwood et al., 1983), reacts to ethidium bromide treatment essentially in the same way as $S$. glaucescens. The fact that pIJ702 was not eliminated with ethidium bromide could be due to its extremely high copy number in this strain (Kieser et al., 1982). The low copy number plasmid pIJ61 derived from the SLP1.2 replicon (Thompson et al., 1982a) was efficiently cured by ethidium bromide. In these cases, the intercalating agent did not only cure plasmids, but in some cases generated plasmid deletions, a phenomenon known for $S$. fradiae (Komatsu et al., 1981) and for $S$. reticuli plasmids (Schrempf \& Goebel, 1979). In addition to these two 'mutational' events, other phenotypic changes occurred, or were increased above the spontaneous rate: loss of sporulation ability, increased chloramphenicol sensitivity and arginine auxotrophy. In spite of the fact that $S$. lividans contains several plasmids (Hopwood et al., 1983) it seems improbable that genes responsible for primary metabolites such as amino acids are plasmid borne. The type of mutation increased by ethidium bromide treatment in $S$. glaucescens and in $S$. lividans also occurs spontaneously at high frequencies when compared with 'classical' chromosomal markers (Hütter et al., 1981; Altenbuchner \& Cullum, 1984). 
We should point out that these 'mutations' do not occur randomly, but appear to be limited to plasmids and to other regions of DNA showing an increased spontaneous genetic instability. All examples of ethidium bromide-generated 'mutations' so far investigated have proved to be deletion events, as demonstrated by DNA hybridization experiments using the cloned structural genes (Schrempf, 1983; Hintermann et al., 1984; Hintermann \& Hütter, 1984). This could suggest an interaction between ethidium bromide and specific DNA regions. Sequence determination of such regions of DNA could be useful in elucidating the type of molecular interaction between 'curing agents' and DNA, and may lead to an understanding of the reasons for the high natural genetic instability in this genus. We conclude that in streptomycetes, ethidium bromide, and probably other DNA-intercalating agents, are potent and probably region-specific mutagens that are also capable of inducing high rates of plasmid loss (curing).

The authors gratefully acknowledge Dr C. J. Thompson for fruitful discussions and critical reading of the manuscript. R.C. gratefully acknowledges a postdoctoral position at Biogen SA.

\section{REFERENCES}

AhMED, Z. U. \& Vining, L. C. (1983). Evidence for a chromosomal location of the genes coding for chloramphenicol production in Streptomyces venezuelae. Journal of Bacteriology 154, 239--244.

Akagawa, H., Okanishi, M. \& Umezawa, H. (1975). A plasmid involved in chloramphenicol production in Streptomyces venezuelae: evidence from genetic mapping. Journal of General Microbiology 90, 336356.

akagawa, H., OKanishi, M. \& Umezawa, H. (1979). Genetic and biochemical studies of chloramphenicol non-producing mutants of Streptomyces venezuelae carrying plasmids. Journal of Antibiotics 32, 610620.

Altenbuchner, J. \& Cullum, J. (1984). DNA amplification and unstable arginine gene in Streptomyces lividans 66. Molecular and General Genetics 195, 134-138.

Crameri, R., Kieser, T., Ono, H., Sanchez, J. \& HÜTTER, R. (1983). Chromosomal instability in Streptomyces glaucescens: mapping of streptomycinsensitive mutants. Journal of General Microbiology 129, 519-527.

Crameri, R., Hintermann, G., Hütter, R. \& Kieser, T. (1984). Tyrosinase activity in Streptomyces glaucescens is controlled by three chromosomal loci. Canadian Journal of Microbiology 30, 1058-1067.

Freeman, R. F. \& Hopwood, D. A. (1978). Unstable naturally occurring resistance to antibiotics in Streptomyces. Journal of General Microbiology 106, 377-381.

Friend, E. J., Warren, M. \& Hopwood, D. A. (1978). Genetic evidence for a plasmid controlling fertility in an industrial strain of Streptomyces rimosus. Journal of General Microbiology 106, 201-206.

Gregory, K. F. \& HuANG, J. C. C. $(1964 a)$. Tyrosinase inheritance of Streptomyces scabies. I. Genetic recombination. Journal of Bacteriology 87 , 1281-1286.

Gregory, K. F. \& Huang, J. C. C. (1964b). Tyrosinase inheritance in Streptomyces scabies. II. Induction of tyrosinase deficiency by acridine dyes. Journal of Bacteriology 87, 1287-1294.

Gregory, K. F. \& SHYU, W. J. (1961). Apparent cytoplasmatic inheritance of tyrosinase competence in Streptomyces scabies. Nature, London 191, 465467.
HintermanN, G. \& Hütter, R. (1984). Structural and functional characterization of two unstable genes of Streptomyces glaucescens. Proceedings of the ASM conference on genetics and molecular biology of industrial microorganisms, Bloomington, Indiana, abstract no. 216, pp. 309-310.

Hintermann, G., Crameri, R., Vögtli, M. \& HütTER, R. (1984). Streptomycin sensitivity by Streptomyces glaucescens is due to deletions comprising the structural gene coding for a specific phosphotransferase. Molecular and General Genetics 196, 513-520.

Hopwood, D. A. (1978). Extrachromosomally determined antibiotic production. Annual Review of Microbiology 32, 373-392.

HOPWOOD, D. A. \& MERRICK, M. J. (1977). Genetics of antibiotic production. Bacteriological Reviews 41, 595-635.

Hopwood, D. A., BibB, M. J., Bruton, C. J., Chater, K. F., Feitelson, J. S. \& Gil, J. A. (1983). Cloning Streptomyces genes for antibiotic production. Trends in Biotechnology 1, 42-48.

HütTER, R., Kieser, T., CRAMERI, R. \& HintermanN, G. (1981). Chromosomal instability in Streptomyces glaucescens. Zentralblatt für Bakteriologie, Mikrobiologie und Hygiene (supplement) 11, 551-559.

KatZ, E., Thompson, C. J. \& Hopwood, D. A. (1983). Cloning and expression of the tyrosinase gene from Streptomyces antibioticus in Streptomyces lividans. Journal of General Microbiology 129, 2703-2714.

KIESER, T. (1984). Factors affecting the isolation of cccDNA from Streptomyces lividans and Escherichia coli. Plasmid 12, 19-36.

KiESER, T., Hopwood, D. A., Wright, H. M. \& Thompson, C. J. (1982). pIJ101, a multi-copy broad host-range Streptomyces plasmid : functional analysis and development of DNA cloning vectors. Molecular and General Genetics 185, 223-238.

Komatsu, K., Leboul, J., Harford, S. \& Davies, J. (1981). Studies of plasmids in neomycin-producing Streptomyces fradiae. In Microbiology 1981, pp. 334337. Edited by D. Schlessinger. Washington, DC: American Society for Microbiology.

Lomovskaya, N. D., Mkrtumian, N. M., GostimsKAYA, N. L. \& DANILENKo, V. N. (1972). Characterization of temperate actinophage C31 isolated from Streptomyces coelicolor A3(2). Journal of Virology 9 , 248-252. 
Malik, V. S. (1977). Preparative method for the isolation of supercoiled DNA from a chloramphenicol-producing streptomycete. Journal of Antibiotics 30, 897-899.

MaLIK, V. S. (1980). Plasmid and chloramphenicol production in Streptomyces venezuelae. Biotechnology Letters 2, 455-457.

Michelson, A. M. \& Vining, L. C. (1978). Loss of chloramphenicol production in strains of Streptomyces species 3022a treated with acriflavine and ethidium bromide. Canadian Journal of Microbiology 24, 662-669.

OKANishi, M. \& UMEZAWA, H. (1978). Plasmids involved in antibiotic production in streptomycetes. In Genetics of the Actinomyceteales, pp. 19-38. Edited by E. Freerksen, I. Tarnok \& J. H. Thumin. Stuttgart \& New York: Gustav Fischer Verlag.

OKanishi, M., Ohta, T. \& UmezaWa, H. (1970). Possible control of aerial mycelium formation and antibiotic production in Streptomyces by episomic factors. Journal of Antibiotics 23, 45-47.

Ono, H., Crameri, R., Hintermann, G. \& Hütter, R. (1983). Hydroxystreptomycin production and resistance in Streptomyces glaucescens. Journal of General Microbiology 129, 529-537.

Pogell, B. M. (1979). Regulation of aerial mycelium formation in streptomycetes. In Proceeding of the $3 \mathrm{rd}$ International Symposium on Genetics of Industrial Microorganisms, pp. 218-224. Edited by O. K. Sebek \& A. J. Laskin. Washington, DC: American Society for Microbiology.

Pridham, T. G., Anderson, P., Foley, C., LindensFELDER, L. A. \& BENEDICT, L. A. (1956/7). A selection of media for maintenance and taxonomic study of Streptomyces. Antibiotics Annual 947-953.
SCHREMPF, H. (1981). Functional aspects of streptomycete plasmids. Zentralblatt für Bakteriologie, Mikrobiologie und Hygiene (supplement) 11, 545-550.

SCHREMPF, H. (1983). Deletion and amplification of DNA sequences in melanin-negative variants of Streptomyces reticuli. Molecular and General Genetics 189, 501-505.

SCHREMPF, H. \& GoEbEL, W. (1979). Function of plasmid genes in Streptomyces reticuli. In Plasmids of Medical, Environmental and Commercial Importance, pp. 259-268. Edited by K. N. Timmis \& A. Pühler. Amsterdam: Elsevier/North-Holland.

Shaw, P. D. \& Piwowarski, J. (1977). Effect of ethidium bromide and acriflavine on streptomycinproduction by Streptomyces bikiniensis. Journal of Antibiotics 30, 404-408.

SUTER, A. M. (1978). Isolierung und Charakterisierung von Melanin-negativen Mutanten aus Streptomyces glaucescens. Thesis no. 6276, Eidgenössische Technische Hochschule Zürich, Switzerland.

Thompson, C. J., Ward, J. \& Hopwood, D. A. (1982a). Cloning of antibiotic resistance and nutritional genes in streptomycetes. Journal of Bacteriology 151, 668-677.

Thompson, C. J., KIESER, T., WARD, J. M. \& HoPwOOD, D. A. $(1982 b)$. Physical analysis of antibiotic resistance genes from Streptomyces and their use in vector construction. Gene 20, 51-62.

VIviAN, A. (1971). Genetic control of fertility in Streptomyces coelicolor A3(2): plasmid involvement in the interconversion of UF and IF strains. Journal of General Microbiology 69, 353-364. 